\title{
Crack and mechanical behavior of CFRP plate-reinforced bridge roofs under high temperature with different anchoring measures
}

\author{
Xin Yuan ${ }^{\mathrm{a}}$ \\ Chaoyu Zhu ${ }^{\mathrm{a}}$ \\ Jiangbei Hu $\mathbf{H u}^{\mathrm{b}}$ \\ Yuye Zhang ${ }^{\text {** }}$ \\ a School of Civil Engineering, Suzhou University of Science and Technology, Suzhou 215011, China. Email: yuanxin9988@163.com, \\ zhuchaoyu@126.com \\ b School of Civil Engineering, Southeast University, Nanjing 210096, China. Email: hujiangbei2011@163.com \\ c Department of Civil Engineering, Nanjing University of Science and Technology, Nanjing 210094, China. Email: zyy@njust.edu.cn \\ ${ }^{*}$ Corresponding author
}

https://doi.org/10.1590/1679-78255575

\begin{abstract}
This paper investigates the crack and mechanical behavior of CFRP plate-reinforced bridge roof under high temperature with different anchoring measures. Six CFRP-reinforced test beams with different anchoring schemes were designed and constructed. The beam specimens, after the high temperature effects, were tested under four-point bending loads. The crack propagation, beam deflection, mid-span strain and the damage modes were observed and recorded until failure. The stiffness variation and the debonding failure mechanism of the test beams were comparatively investigated. The results indicate that the debonding bearing capacity of the specimens can be improved by the additional anchoring measures. The concrete shrinkage at the crack and the average crack spacing are more effectively reduced, when the additional anchoring measures are placed at the mid-span and the support position. In addition, a theoretical model is proposed for calculating the intermediate crack debonding bearing capacity. Based on the comparative analysis of various models and test results, it is shown that the proposed model could accurately calculate the intermediate crack debonding bearing capacity of the test specimens.
\end{abstract}

\section{Keywords}

Bridge roof reinforcement, CFRP plate, debonding damage, crack propagation, anchoring scheme, bearing capacity

\section{INTRODUCTION}

Several approaches have been developed to strengthen existing reinforced concrete structure. Compared to the traditional method of steel plate-bonding reinforcement, the externally bonded carbon fiber-reinforced polymer (CFRP) reinforcement has many advantages. Kondratenko and Ding (2018) investigated the destruction types of the CFRP reinforced concrete structures, and a new calculation method for preventing the delamination of the CFRP from concrete structures was proposed. Mashrei et al. (2019) employed grooving technique to improve the flexural capacity of CFRP strengthened beams, and it was found that CFRP with grooves could effectively delay the debonding failure of CFRP from the concrete surface. A variety of studies have focused on the mechanical properties and performances of existing structural members reinforced by CFRP. Abbasloo and Maheri (2017) studied the modal characteristics of CFRP composite and designed a method to easily analyze the modal properties of CFRP-Honeycom sandwich panels. Shukri et al. (2018) investigated the mechanism of the interfacial crack debonding and introduced the moment-rotation 
method to simulate the debonding of hybrid CFRP strengthen method. It was found that CFRP with higher elastic modulus had adverse effect on the interface of CFRP and concrete. Jiang et al. (2015) studied the prestressed CFRP reinforced RC beams, and proposed a formula for calculating the reliability of deflection and crack width by considering the prestressed conditions. In recent years, the CFRP reinforcement method have been increasingly used in bridge structures. The analysis of girder bridge reinforced by CFRP has been carried out by Kohnehpooshi and Jaafar (2017) and Yang et al. (2017). Flexural tests were conducted on the prestressed concrete bridge deck with CFRP tendons. The stress states and failure modes of the CFRP tendons were given. Chen et al. (2018) applied the CFRP in the bridge pier reinforcement and conducted the quasi-static tests. It was found that the load-carrying capacity and anti-deformation ability of the bridge pier can be significantly improved by CFRP. Hosseini et al. (2019) performed the truck-loading tests on an old roadway bridge by CFRP reinforcement. It was found that the mismatch of the CFRP-steel thermal expansion coefficient negative effect can be reduced at a low air temperature.

Since the CFRP-concrete interface bond strength is usually small, the interface layer is prone to debonding failure under large loads. Reasonable anchorage methods can effectively prevent or delay the occurrence of the debonding of CFRP-concrete interface (Ceroni and Pecce, 2010). Al-Mahaidi and Kalfat (2011) made a beneficial attempt to increase the CFRP-to-concrete bond beyond the provision of effective bond length, which involved the use of additional CFRP material to expand the CFRP bonding area. Galal and Sekar (2008) adopted the mechanical fasteners to increase the CFRP-to-concrete bond strength, resulting in the improvement of CFRP-to-concrete bond strength. Qazi et al. (2013) analyzed specimens with anchorages of CFRP strip techniques from their failure modes and ultimate capacity. It was found that the CFRP anchorage measures had a positive effect on the overall performance of CFRP strengthened structures. Wu et al. (2010) investigated the intermediate crack-induced debonding of CFRP reinforced RC beams with CFRP enhancement, which demonstrated the effectiveness of CFRP in preventing intermediate crack debonding. Mertoğlu et al. (2016) conducted 14 concrete specimens by externally bonded CFRP. A modified bond slip model was proposed by comparing with the model proposed for system without anchoring. It can be concluded that the increasing application of dowel anchorages could significantly increase the bond stress of CFRP-concrete interface. Since the CFRPconcrete interface of the bridge roof is usually subjected to large bending moments and stresses, more emulative anchoring method is required to prevent the interface debonding, thereby enhancing the structural bearing capacity.

The bridge roofs are always subjected to the coupling of a variety of loads and environment conditions, such as the temperature effects, during their service life (Luo, 2018). The experimental fatigue performance of CFRP plate reinforced under hot-seawater environment and cyclic loads coupled action was investigated. Recent researches have investigated the mechanical properties of CFRP reinforced concrete structures under high temperature. Hong et al. (2016) and Wang et al. (2017) analyzed the long-term performance of concrete-CFRP interface under the combined impacts of temperature and sustained loads. The basis of the durability design was proposed for the high strength concrete structures reinforced by CFRP. Several studies (Biosca et al., 2019; Ferrier and Agbossou, 2017; Lin et al., 2019; Lopez et al., 2003) focused on the flexural and fatigue properties of concrete beams strengthened with CFRP plates under temperature field. It can be concluded that the high temperature condition has an adverse effect on the bearing capacity of interfacial debonding. However, most previous studies have not quantitatively investigated the crack development and mechanical properties of the CFRP-reinforced bridge roof under high temperature, and little attention had been given to the reasonable CFRP anchoring schemes in a hot environment.

The interfacial debonding of CFRP plate-concrete is an inevitable problem in the reinforcement structures, which would lead to premature failure of CFRP plate at anchorage point. Recent years, several researches have been conducted on the interfacial debonding of CFRP plate-concrete. However, few studies focus on the effective anchoring method of CFRP plate reinforced bridge roof at high temperature. Aiming at closing the gap, we studied the interfacial debonding problem especially for the bridge roof with different CFRP anchoring measures, under high temperature effect of paving asphalt. A theoretical model was proposed for calculating the intermediate crack debonding bearing capacity of the CFRP reinforced bridge roofs. Based on the comparison with the test results, it can be found that the calculating model proposed in this paper is more suitable for the CFRP reinforced bridge roofs, compared to the models used in the previous literature.

This paper investigates the crack and mechanical behavior of CFRP plate-reinforced bridge roof under high temperature with different anchoring measures. Taking Bangabandhu bridge roof as the research background, the bridge roof reinforcement schemes with different CFRP anchoring measures were designed firstly. Six CFRP-reinforced test beams were then tested under four-point bending loads. The crack propagation, mid-span strain, deflection, and flexural capacity of the anchoring beams were comparatively analyzed. In addition, typical failure modes of the CFRP platereinforced concrete specimens were carefully studied, and the debonding bearing capacity and crack development 
features were then obtained. Finally, the calculation model of the intermediate crack debonding bearing capacity was proposed to quantify the debonding capacity of the CFRP reinforced bridge roofs.

\section{CRACKS OF A BRIDGE ROOF AND THE CFRP REINFORCEMENT}

The Bangabandhu Bridge serves as the connection between Central Asia and Northwestern Europe. Cracks appeared in the early stages of bridge construction, seventeen different types of longitudinal cracks were found on the bridge roof, which were mainly caused by the temperature and shrinkage stress. The crack morphology is shown in Figure 1.
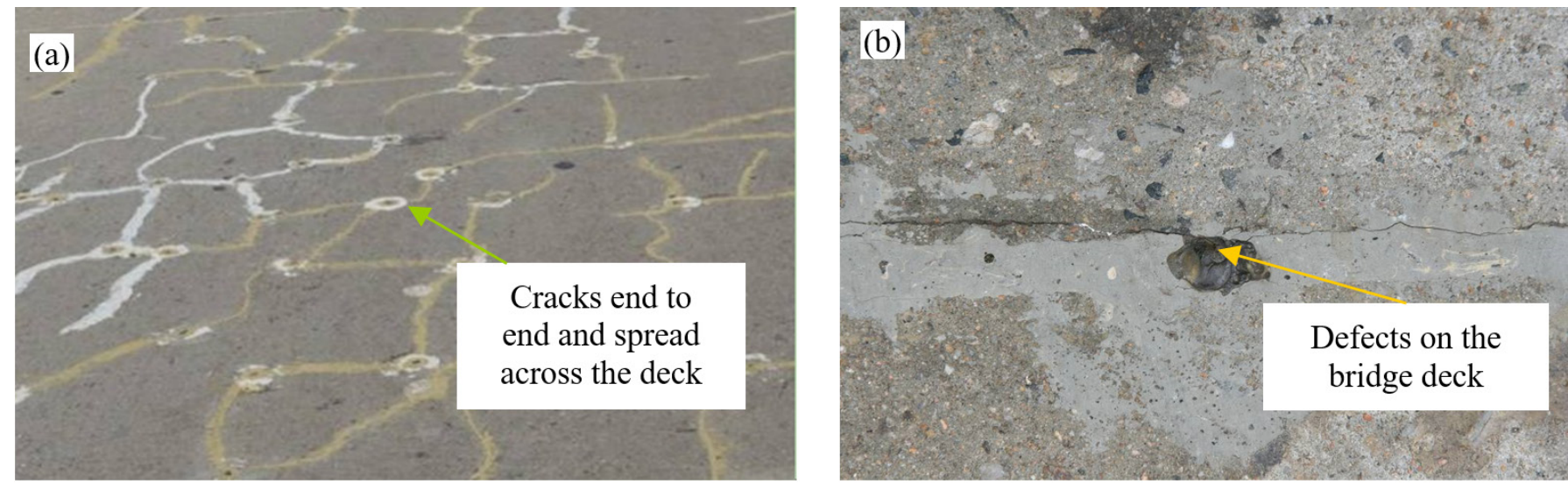

Figure 1 Cracks on Bangabandhu bridge: (a) partial crack in the bridge deck pavement; and (b) defects on the bridge deck pavement.

A CFRP plate repair and reinforcement scheme was proposed to reduce and control the development of longitudinal cracks in the bridge roof deck. The main procedure included: 1) the epoxy resin was grouted into the cracks on the bridge deck; 2) the CFRP plates with a width of $100 \mathrm{~mm}$ and a thickness of $1.4 \mathrm{~mm}$ were applied horizontally in four lanes of the bridge to constrain the development of longitudinal cracks; 3 ) leveled the bridge deck and set the insulating layer and waterproof layer; and 4) paved the SMA wear resistant layer with a thickness of $5 \mathrm{~cm}$. Figure 2 illustrates the deck paving scheme of the bridge roof.

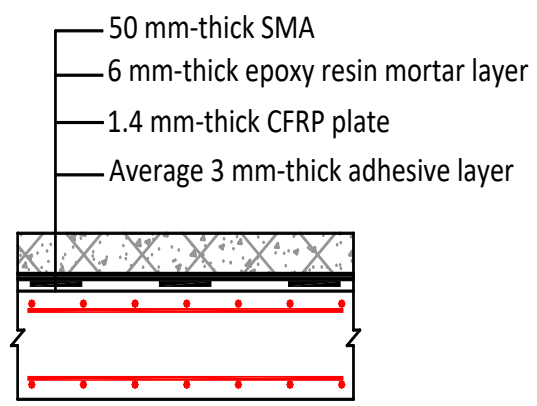

Figure 2 Schematic diagram of the deck paving scheme of the bridge roof.

\section{EXPERIMENTAL PROGRAM}

In order to study the debonding failure of the bridge reinforced by CFRP plates under high temperature asphalt paving, the high temperature and tests of CFRP plate-reinforced specimens were conducted. The debonding failure modes of CFRP plates with different anchoring were compared in detail. In the test, the high temperature in the asphalt pavement construction of Bangabandhu Bridge was simulated and measured to evaluate the influence of high temperature on the reinforcement effect of CFRP plates.

\subsection{Temperature simulation and measurement}

In order to simulate the high temperature effect on the CFRP plates during the asphalt paving process and the vehicle load effect, the specific fabrication sequence of the specimen was as follows: 1) the CFRP plate-reinforced specimens were cured for 3 to 7 days; 2) the surface of the specimens were coated with latex paint as a protective layer; 3 ) asphalt was paved on site for high temperature simulation and rolling (shown in Figure 3). Figure 4 shows the test site 
of the asphalt paving and rolling. It can be seen from Figure 4 that the maximum temperature of the asphalt surface layer reaches $172{ }^{\circ} \mathrm{C}$. After 60 minutes, and the bottom of the asphalt surface returned to about $67^{\circ} \mathrm{C}$.
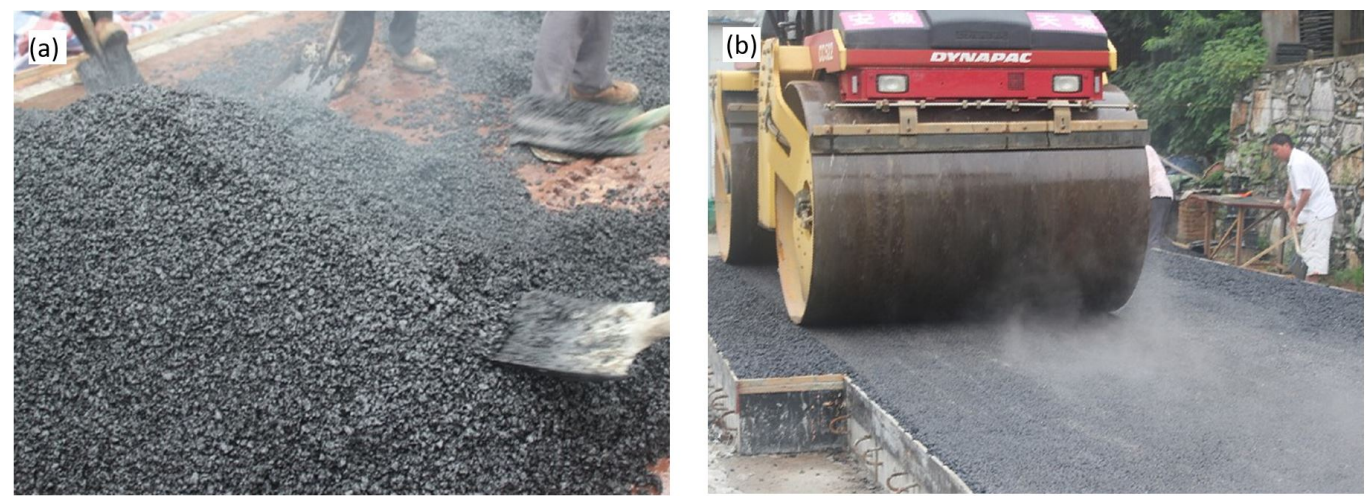

Figure 3 Test site: (a) the paving process of SMA; and (b) the rolling process of SMA.

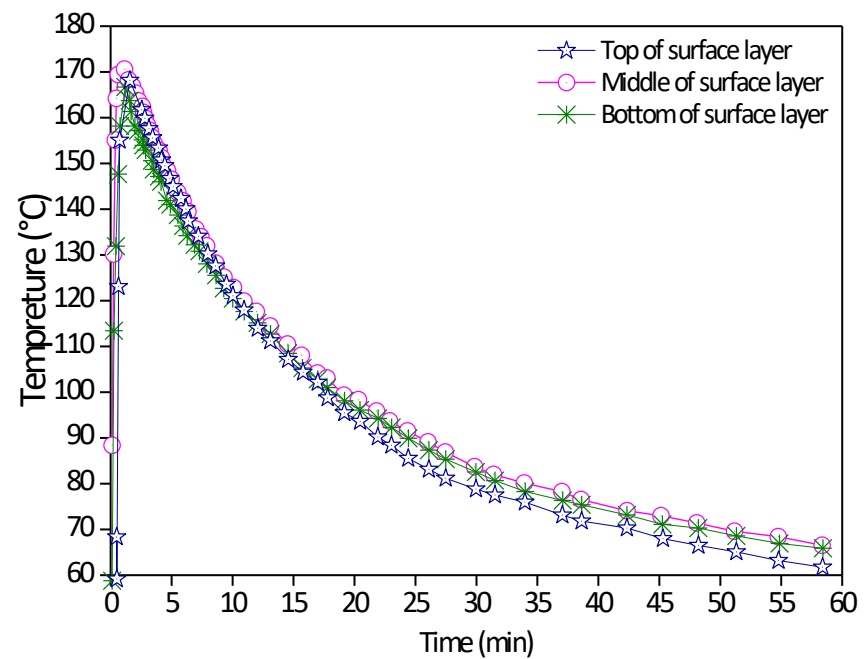

Figure 4 Different locations in the asphalt surface temperature curve changes with time.

Figure 5 illustrates the temperature-time curves of the CFRP plate in the test. It can be seen from the figure that the temperature on the upper and the lower sides of the CFRP plate changes significantly in the ascending section of the temperature curve, while the temperature curve in the descending section tends to be flat. The highest temperature of the upper and lower sides of the CFRP plate are respectively $72.7^{\circ} \mathrm{C}$ and $64.8^{\circ} \mathrm{C}$, the temperature variations of the CFRP plates are relatively large.

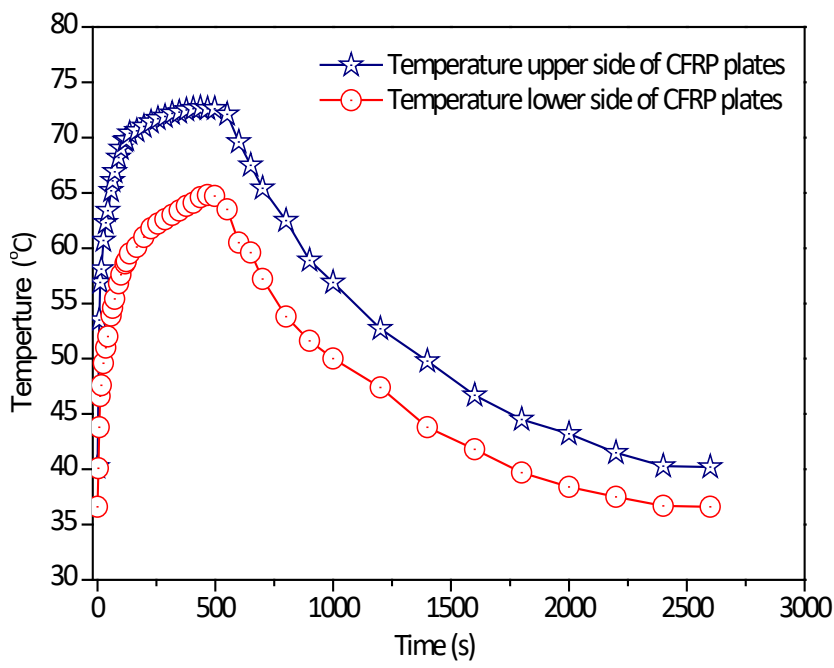

Figure 5 Temperature-time curves of the test CFRP plate. 
According to the storage modulus curves proposed by Cheng (2016), the CFRP plate-concrete interfacial adhesion properties may change under high temperature. The surface-bonded CFRP reinforced beams could experience premature debonding failure in the high temperature environment. Thus, in this paper, the additional anchoring measures are taken on the CFRP-reinforced specimens after the high temperature action, to ensure the good effect of the CFRP reinforcement.

\subsection{Test scheme of bridge roof reinforcement}

According to the Bangabandhu bridge roof beam, the CFRP plate-reinforced specimens was designed as $4.00 \mathrm{~m}$ in length, $0.65 \mathrm{~m}$ in width and $0.28 \mathrm{~m}$ in height. Figure 6 shows the summary of test specimens for investigation.

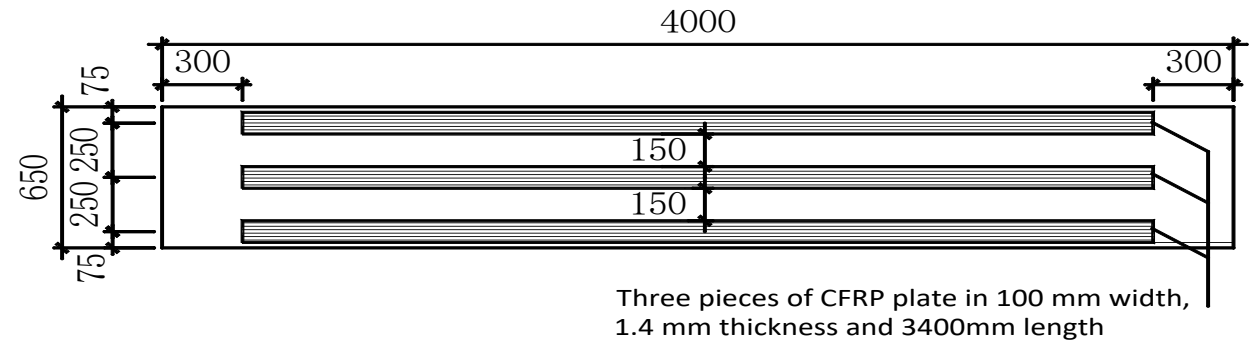

Figure 6 Design of reinforcement (unit: $\mathrm{mm}$ )

The specimens were divided into two types: the contrast specimens and the reinforcement specimens(Group A and Group B). Different reinforcement schemes were tested and analyzed for further study of the reinforcement measures with different CFRP plates. In order to compare the reinforcement effect of CFRP plates under different anchorage measures, six different anchorage schemes were adopted as additional anchorage measures for the reinforcement of specimens. The classification and specific parameters of specimens are shown in Table 1 . The different schemes of additional anchoring measures of the specimens are shown in Figure 7. Figure 7(a) shows specimens in Group A without additional anchorage measures. Specimens additionally anchored by sticking strips at different positions are presented in Figures $7(b)$ to (d), and specimens with bolt anchorage measures at different positions are illustrated as Figures $7(\mathrm{e})$ to (g).

Table 1 Summary of test specimens.

\begin{tabular}{ccccc}
\hline $\begin{array}{c}\text { Grouping of } \\
\text { specimens }\end{array}$ & $\begin{array}{c}\text { Specimen } \\
\text { number }\end{array}$ & $\begin{array}{c}\text { Reinforcement } \\
\text { measures with CFRP }\end{array}$ & $\begin{array}{c}\text { Additional measure taken by anchoring } \\
\text { the CFRP plate }\end{array}$ & Purpose \\
\hline $\begin{array}{c}\text { Contrast } \\
\text { Specimen } \\
\text { Group } \\
\text { A }\end{array}$ & FDBL & None & No additional anchorage measure & Beam for Comparison \\
number
\end{tabular}




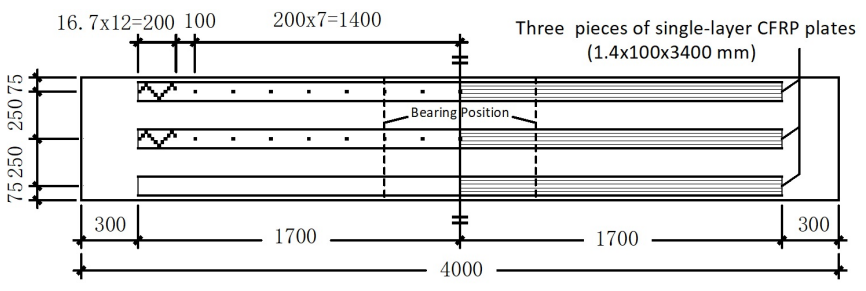

(a) Specimens in Group A

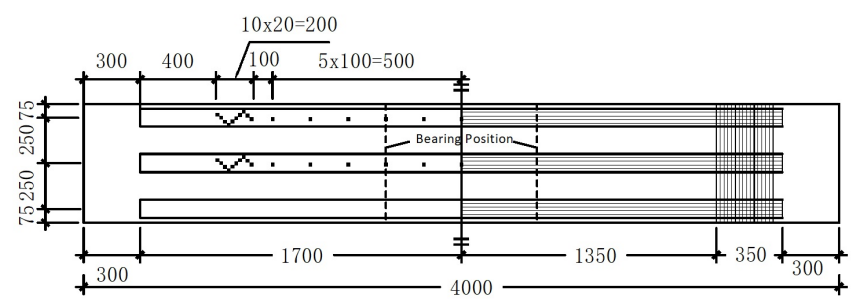

(b) Specimen TM-1 (anchoring transversely by pasting strips at the ends of the specimens)

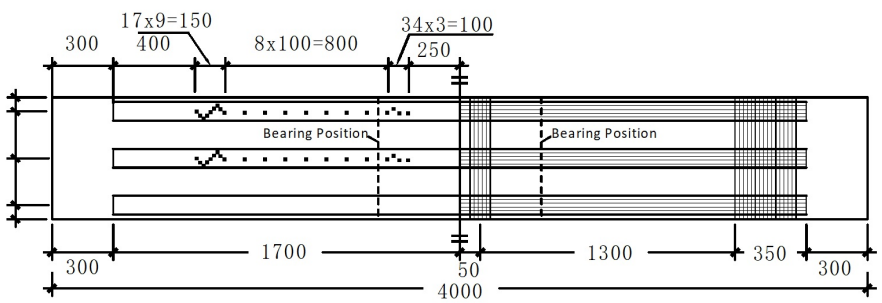

(c) Specimen TM-2 (anchoring transversely by pasting strips at the ends and middle of the specimens)

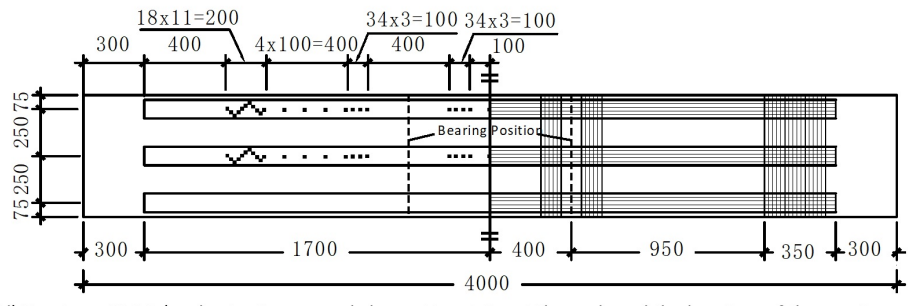

(d) Specimen TM-3 (anchoring transversely by pasting strips at the ends and the bearings of the specimens)

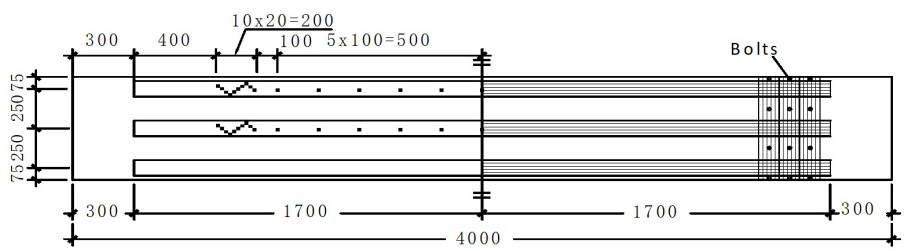

(e) Specimen LM-1 (anchoring transversely by pasting strips and bolting at the ends of the specimens)

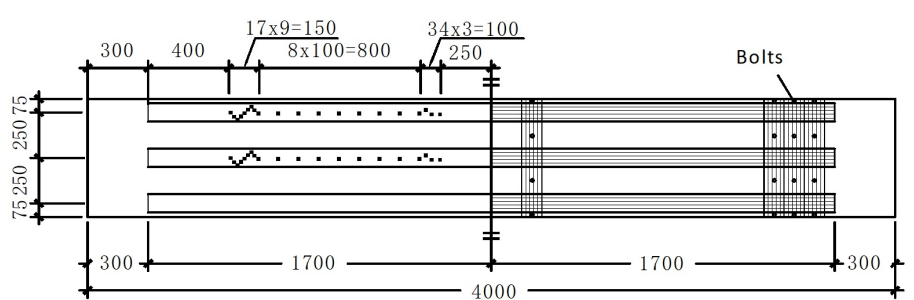

(f) Specimen LM-2 (anchoring transversely by pasting strips and bolting at the ends and middle of the specimens)

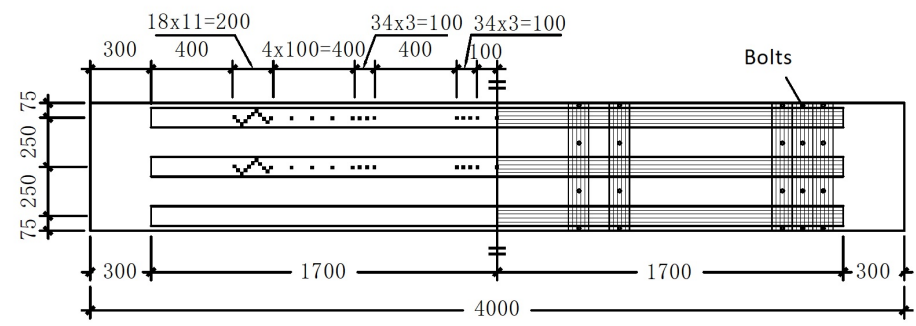

(g) Specimen LM-3 (anchoring transversely by pasting strips and bolting at the ends and bearings of the specimens)

Figure 7 Different schemes of additional anchoring measures. 
The performance parameters of the CFRP plate, including tensile strength, tensile modulus and elongation at break, are shown in Table 2. The measurement performance parameters of the adhesive, including tensile strength, tensile modulus, flexural strength and compressive strength are shown in Table 3. Concrete with a compressive strength of 21.1 MPa and steel with a tensile strength of $360 \mathrm{MPa}$ were adopted in the tests.

Table 2 Measured performance indexes of CFRP plate.

\begin{tabular}{cccc}
\hline Thickness $(\mathbf{m m})$ & Tensile strength (MPa) & Tensile modulus (GPa) & Elongation at break (\%) \\
\hline 1.4 & $2300-2400$ & $150-155$ & $1.4-1.42$ \\
\hline
\end{tabular}

Table 3 Measured performance indexes of interface adhesive bonding layer.

\begin{tabular}{|c|c|c|c|c|}
\hline Model & $\begin{array}{l}\text { Tensile strength } \\
\text { (MPa) }\end{array}$ & $\begin{array}{l}\text { Tensile modulus of elasticity } \\
\text { (MPa) }\end{array}$ & Bending strength (MPa) & $\begin{array}{c}\text { Compressive strength } \\
\text { (MPa) }\end{array}$ \\
\hline $\mathrm{K}-801$ & $25-26$ & $2500-2600$ & $30-32$ & $70-75$ \\
\hline
\end{tabular}

A 30-ton hydraulic jack new bridge was applied in the test specimens. Firstly, a load of $5 \mathrm{kN}$ was applied to the test piece for preloading, and then the load per stage was increased by $20 \mathrm{kN}$. Figure 8 presents the diagram of the test system. Figure 9 shows a representative specimen in the test rig. Figure 9 shows a representative specimen in the test rig. Figure 9 (a) presents the specimen before the bending test. Asphalt layer was paved on the specimens, and the high temperature effect of the asphalt acted on the CFRP-reinforced specimen. After the bending test was completed, the asphalt surface layer was removed to facilitate the observation of the debonding of the interface between the CFRP plate and concrete. Figure 9(b) shows the specimen with asphalt layer partially removed after the bending test. The failure of the specimen during the test is characterized by the yielding of the steel, the fracture of the concrete and the peeling of the CFRP plates.

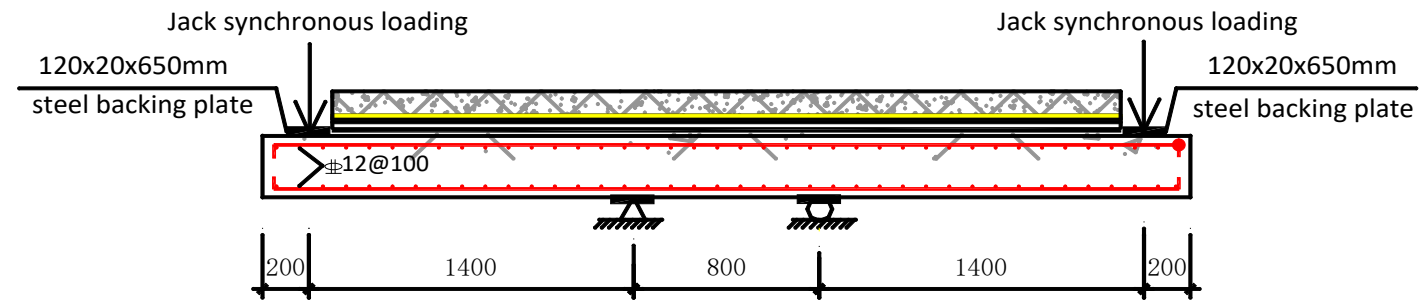

Figure 8 Diagram of the test system.
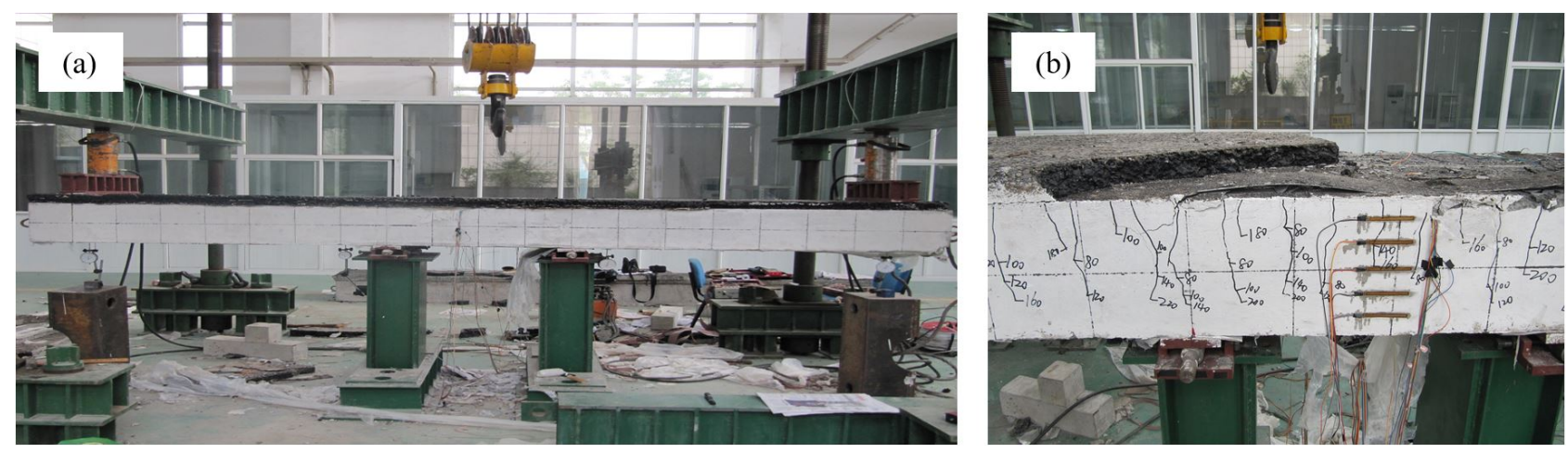

Figure $9 \mathrm{~A}$ representative specimen in the test rig: (a) Specimen before the bending test; and (b) Specimen with asphalt layer partially removed after the test.

\section{EXPERIMENTAL RESULTS AND ANALYSIS}

\subsection{Fracture morphology and crack propagation}

Figure 10(a) presents the fracture morphological distribution of unreinforced Specimen FDBL. Figures 10(b) to (d) show the crack distribution of three specimens reinforced by CFRP plates. Figures $11(a)$ to (f) illustrate the fracture morphological distribution of the CFRP reinforced specimens with different additional anchoring measures. It can be 
seen from the figures 10 and 11 that the flexural main crack appeared first and was almost perpendicular to the tensile side of the member at the beginning of the formation and development of the crack. The root cracks were located near the position of the steel bars, mainly appeared at the moment when the member was close to failure.

(a) FDBL

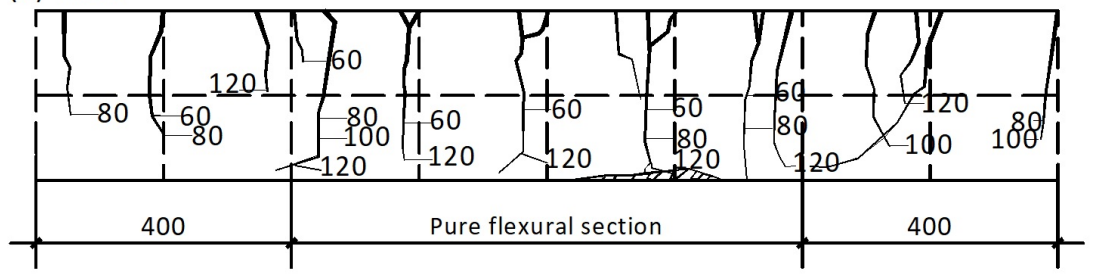

(b) FX-1

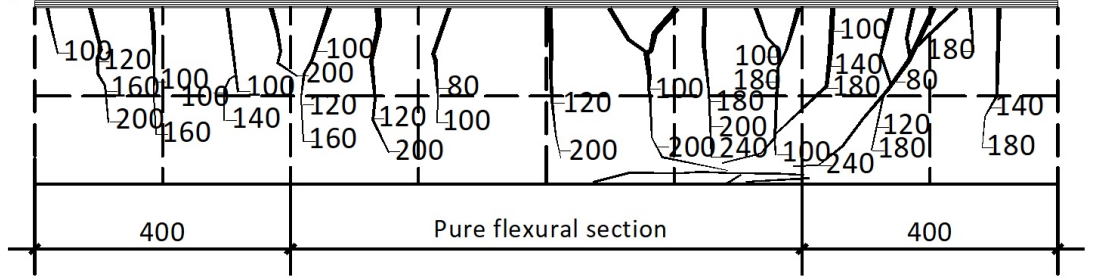

(c) FX-2

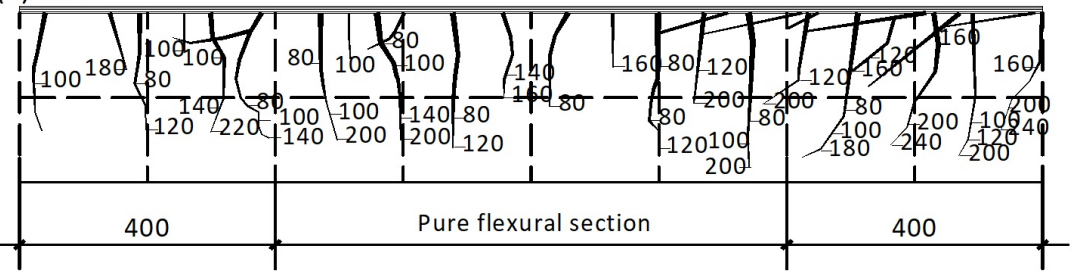

(d) $\mathrm{FX}-3$

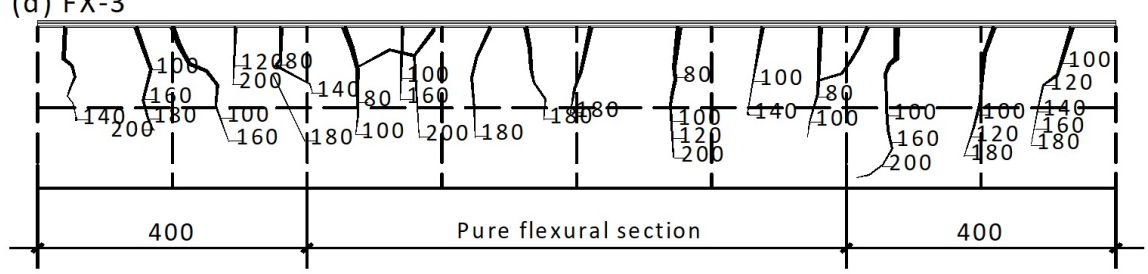

Figure 10 Crack distribution of Specimen FDBL and the specimens in Group A: (a) Specimen FDBL; (b) Specimen FX-1; (c) Specimen FX-2; and (d) Specimen FX-3. 
(a) TM-1

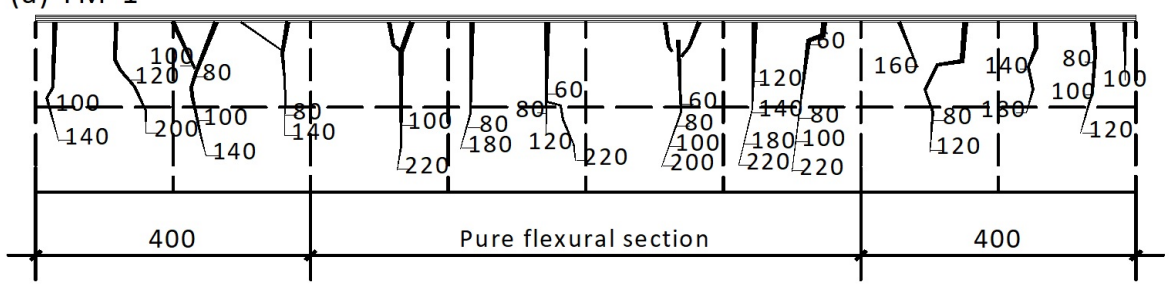

(b) $\mathrm{TM}-2$
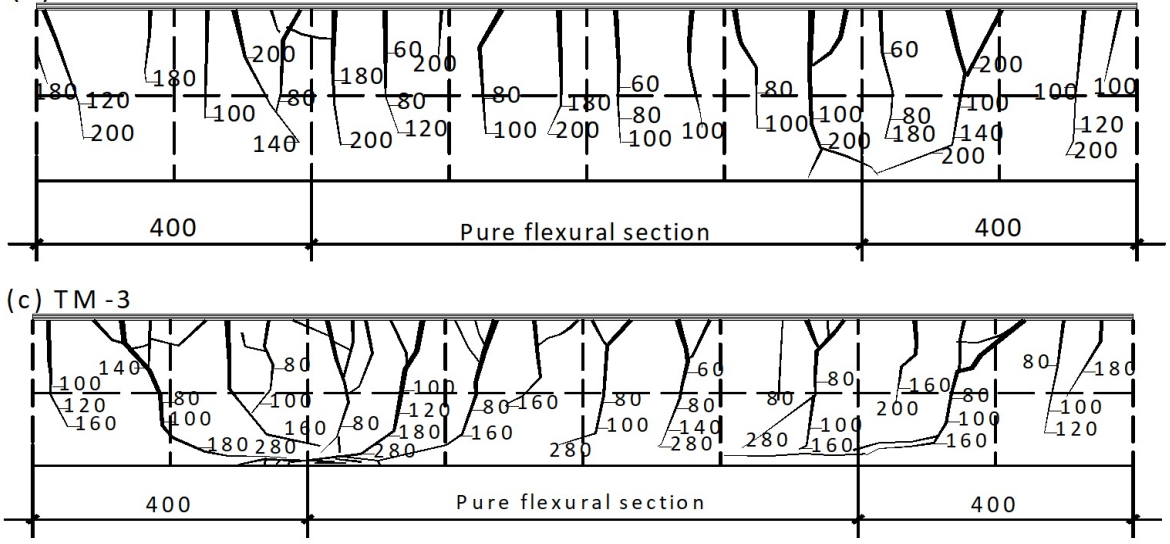

(d) LM-1

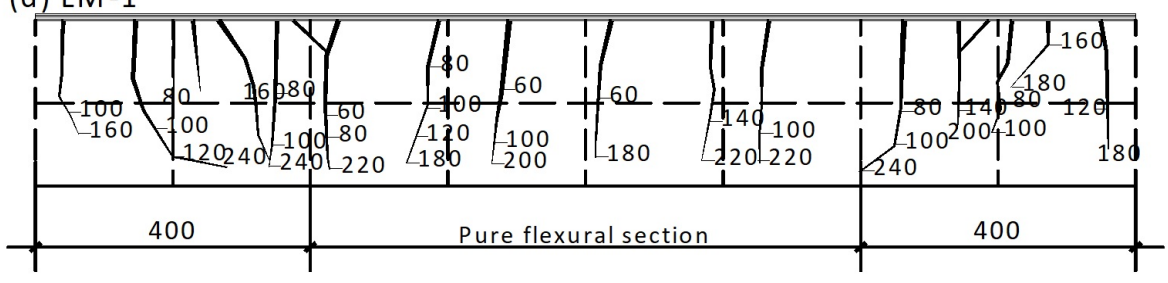

(e) LM -2

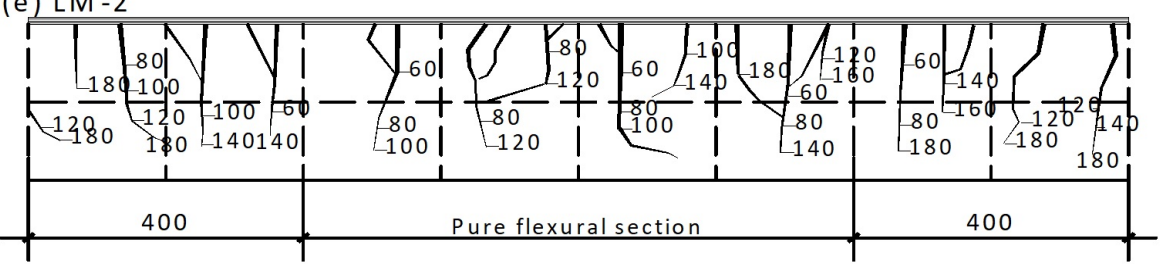

(f) $L M-3$

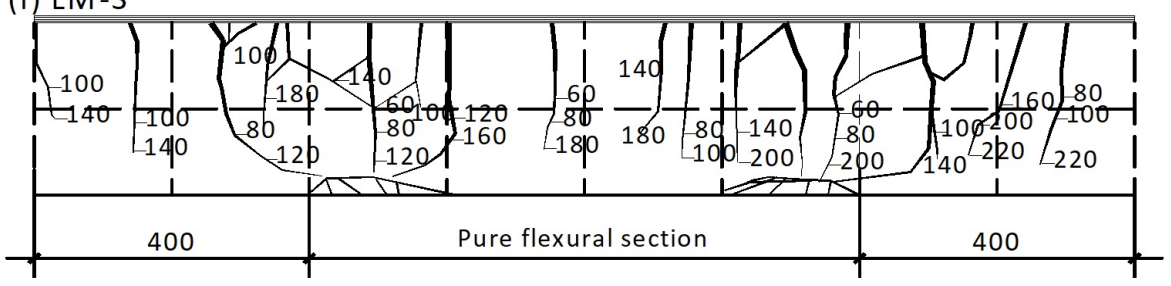

Figure 11 Crack distribution of specimens of Group B with additional anchoring measures: (a) Specimen TM-1; (b) Specimen TM-2; (c) Specimen TM-3; (d) Specimen LM-1; (e) Specimen LM-2; and (f) Specimen LM-3.

As can be seen from Figures 10(a), the crack pitch and width in the purely curved portion of the comparative specimen FDBL were large. The crack shape of the comparative specimen FDBL was roughly triangular because it did not have a CFRP plate attached. The crack width of the concrete surface is the largest. As the crack height increases, the crack width gradually decreases.

For the specimens in Group A, the CFRP plate was adhered to the surface of specimen. Therefore, the interfacial bond shear stress between concrete and CFRP plate prevented the shrinking of the concrete under tension near the cracking section. The cracks present the shape of the jujube, as shown in Figures 10(b) to (d). The crack distribution of the specimen in Group B is characterized by a small crack pitch and a crack width in the purely curved region, as shown 
in Figure 11. It should be pointed out that the specimens TM-3 and LM-3 present flexural shear cracks in the vicinity of the bearing, as illustrated in Figures 11(c) and (f). As the load increases, the crack develops toward the compression zone of the concrete in the direction of the support.

Table 4 lists the crack distribution of the pure flexural region of the specimen. It can be seen from Table 4 that the ratio of the maximum crack spacing to the average crack spacing is between 1.33 and 2.92, and the ratio of the maximum crack spacing to the minimum crack spacing is between 1.09 and 1.55. The rising height of the main flexural crack in the pure flexural region of the specimen FDBL was $260.1 \mathrm{~mm}$. Due to the enhanced constraint of the CFRP plate, the maximum height of the bending main crack of the Group A and Group B specimens is $245.8 \mathrm{~mm}$, which is smaller than the maximum height of the bending main crack of the specimen FDBL.

Table 4 Crack distribution in the pure flexural sections of specimens.

\begin{tabular}{|c|c|c|c|c|c|c|c|}
\hline $\begin{array}{l}\text { Specimen } \\
\text { number }\end{array}$ & $\begin{array}{l}\text { Number of } \\
\text { cracks }\end{array}$ & $\begin{array}{l}\text { Maximum crack } \\
\text { spacing } l_{\max } \\
(\mathrm{mm})\end{array}$ & $\begin{array}{c}\text { Minimum crack } \\
\text { spacing } l_{\max }(\mathrm{mm})\end{array}$ & $\begin{array}{l}\text { Mean crack } \\
\text { spacing } l_{m} \\
\text { (mm) }\end{array}$ & $l_{\max } / l_{m}$ & $l_{\max } / l_{\min }$ & $\begin{array}{l}\text { Maximum rise } \\
\text { height of cracks } \\
(\mathrm{mm})\end{array}$ \\
\hline FDBL & 5 & 183.6 & 137.7 & 168.2 & 1.09 & 1.33 & 260.1 \\
\hline FX-1 & 7 & 175.5 & 81.5 & 129.2 & 1.36 & 2.15 & 215.2 \\
\hline FX-2 & 8 & 146.0 & 78.6 & 102.2 & 1.43 & 1.86 & 232.2 \\
\hline FX-3 & 8 & 155.3 & 73.2 & 101.1 & 1.54 & 2.12 & 234.2 \\
\hline TM-1 & 6 & 174.6 & 95.2 & 127.0 & 1.37 & 1.83 & 235.2 \\
\hline TM-2 & 8 & 141.5 & 73.2 & 105.2 & 1.35 & 1.93 & 234.8 \\
\hline TM-3 & 7 & 144.8 & 65.5 & 115.0 & 1.26 & 2.21 & 245.8 \\
\hline LM-1 & 6 & 151.9 & 77.8 & 123.0 & 1.23 & 1.95 & 241.5 \\
\hline LM-2 & 6 & 150.0 & 77.8 & 115.6 & 1.30 & 1.93 & 215.0 \\
\hline LM-3 & 8 & 158.3 & 54.2 & 102.4 & 1.55 & 2.92 & 237.2 \\
\hline
\end{tabular}

Figure 12 shows the variation of the load-crack curves of the specimens. The tensile stress un-reinforced specimen (Specimen FDBL) is transmitted only by the bond between steel and concrete. The tensile stress of CFRP Plate-reinforced specimens can also be shared by steel bars and CFRP plates. The additional anchoring reinforcement of the CFRP plate effectively reduces the tensile stress and strain values of the steel bar. The stress gradient value and crack width of the specimens gradually decrease with the reinforced effect of the CFRP plate.

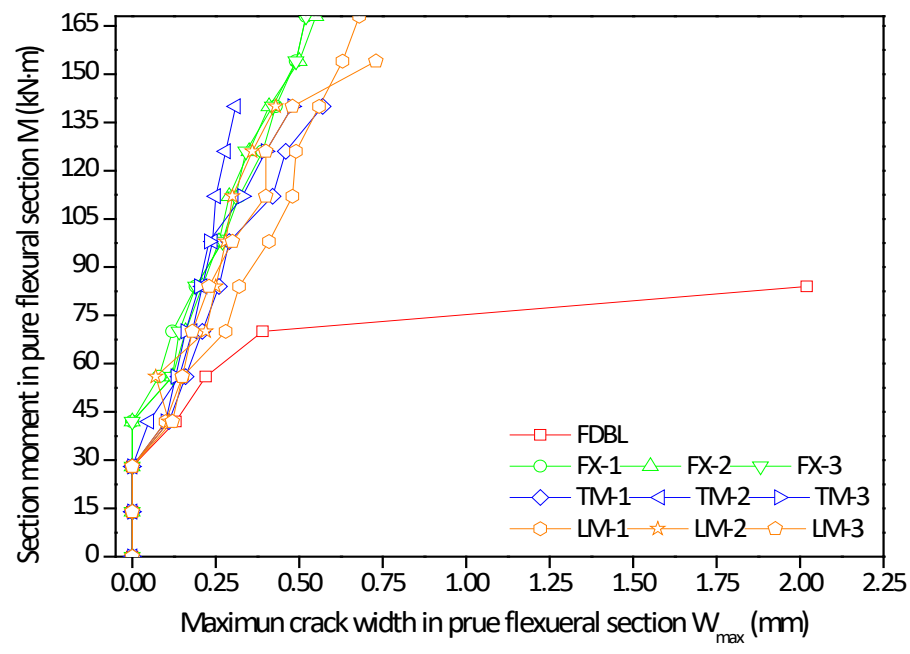

Figure 12 Load-crack curves of specimens.

In this paper, the specimens in Group B are affixed with transverse strips at different locations as an additional anchoring measure. Figure 13 shows the average crack spacing of the specimens with different additional anchoring measures. The average crack spacing and the maximum crack width of the specimens with additional anchoring measures at the purely curved section and the support position have the most significant reduction effect. It can be seen from Fig. 14 that the maximum crack width of the specimens LM-3 and TM-1 is similar to the specimen FDBL before the load 
reaches $0.8 M_{y}$, and when loaded to $0.9 M_{y}$. The maximum crack width of the specimen LM-1 and the specimen TM-1 are significantly reduced compared to the maximum crack width of the specimen FDBL. There are two reasons for the above phenomenon: 1) the number of curved main cracks gradually decreases as the root crack propagation increases; 2 ) the strain gradient of concrete gradually decreases with the effect of additional anchoring.

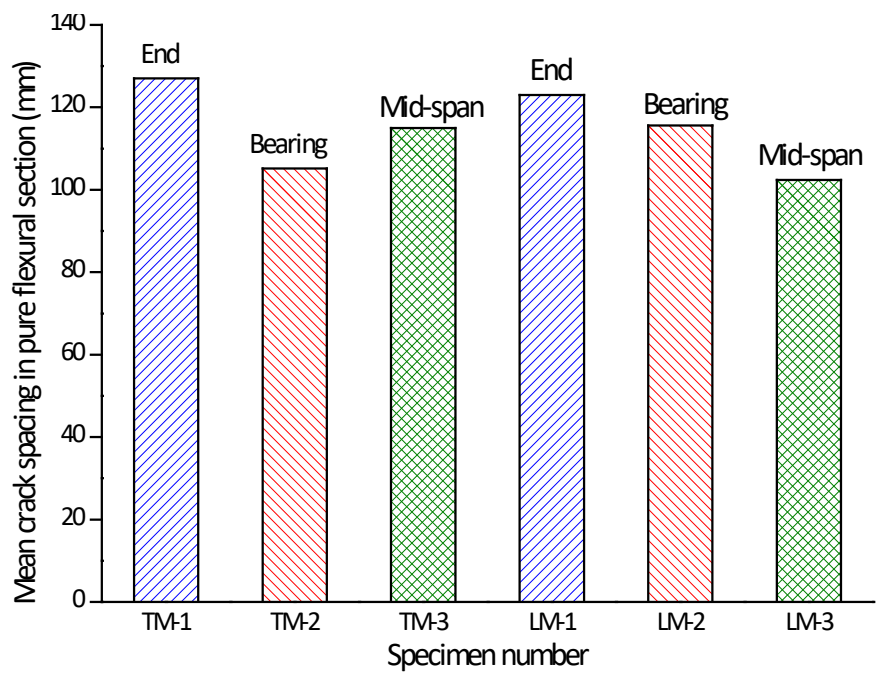

Figure 13 Comparison of the mean crack spacing of the specimens with different additional anchoring measures.

Figure 14 shows that the mean crack spacing of specimen LM-2 and LM-3 are reduced by $6.02 \%$ and $16.75 \%$, respectively, compared to that of the specimen LM-1. It indicates that the additional bolt anchoring measures in the midspan and the bearing positions were more effective. The statistics shows that the maximum crack width of the specimen LM-2 and the specimen LM-3 are reduced by $23.21 \%$ and $14.26 \%$, respectively, comparing with the specimen LM-1 with end bolt anchoring measure. The additional bolt anchoring measure in mid-span position has most effective in reducing the maximum crack width.

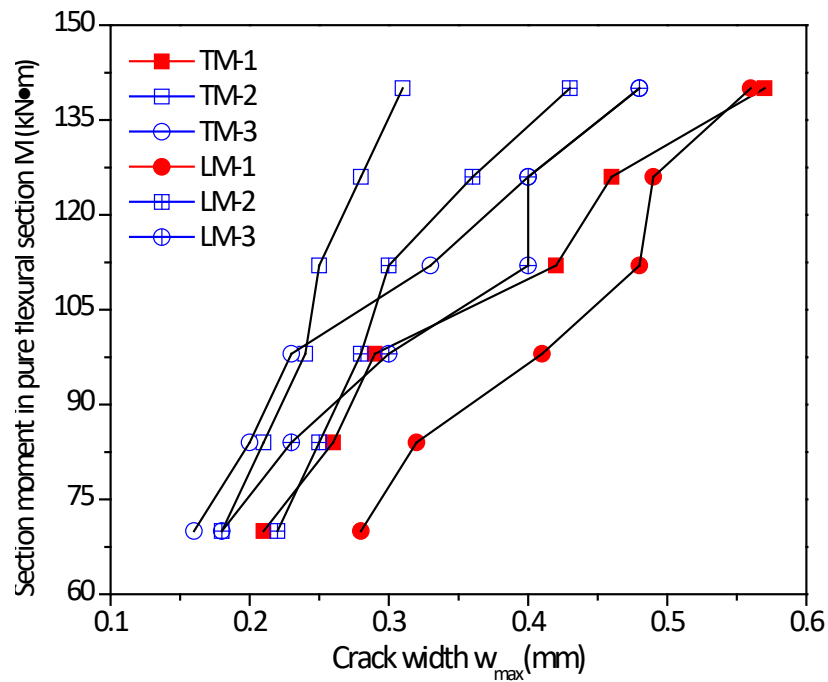

Figure 14 Comparison of the maximum crack width for specimens with different additional anchoring measures.

\subsection{Mid-span load-deflection curve}

Figure 15 shows the variation of the load-deflection curves of the specimens. It can be seen from Figure 15 that the cracking load values of the specimens reinforced by the CFRP plates are approximately the same. The tensile stress is shared by the CFRP plate and the steel bar when the concrete is cracked. With the gradual increase of CFRP tensile strength, the cracking of the specimen beam strengthened by CFRP plate is obviously delayed and the rigidity is improved. 


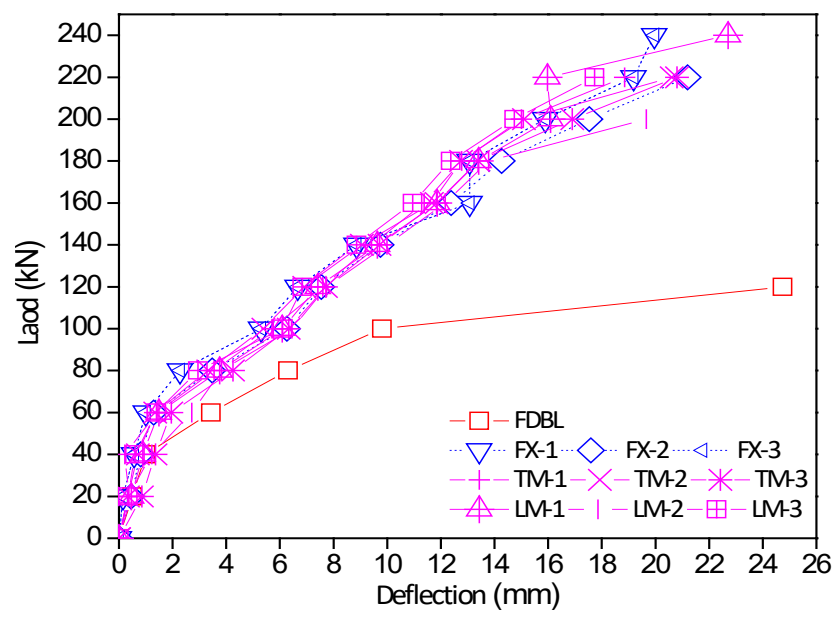

Figure 15 Load-deflection curves.

It can be seen from Figure 16 that the strains of steel bars of CFRP plate-reinforced specimen increase slowly after the occurrence of the cross-section crack. Since the CFRP plate and the steel bar share the tensile stress that the loadstrain curve trend of the CFRP plate-reinforced specimens are steeper than that of the un-reinforced specimen FDBL. The CFRP plate has a good reinforcing effect in the specimens of bridge roof.

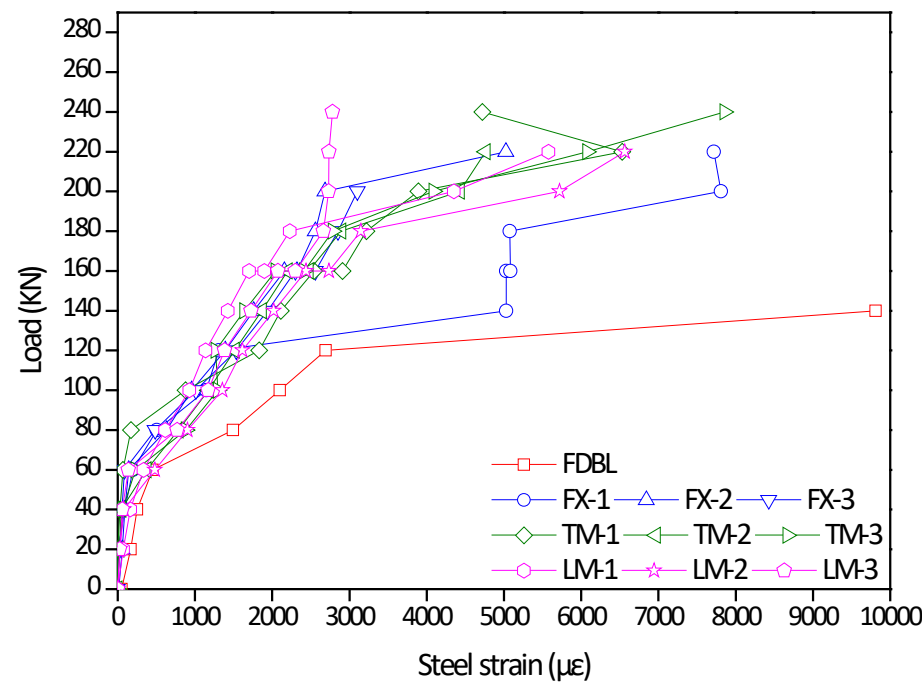

Figure 16 Load-strain curves of reinforcing steel bar.

\subsection{Development of CFRP plate strain}

It can be seen from Figure 17 that the variations of the strain curve of CFRP plates are similar. Taking specimen TM-2 as an example, when the load reaches $240 \mathrm{kN}$, the strain curve of the CFRP plate in the flexural shear section is almost horizontal. This indicates that the reinforcement effect of the CFRP plate can be improved by the anchoring reinforcement methods, and the occurrence of debonding of the CFRP plate can be effectively limited. 

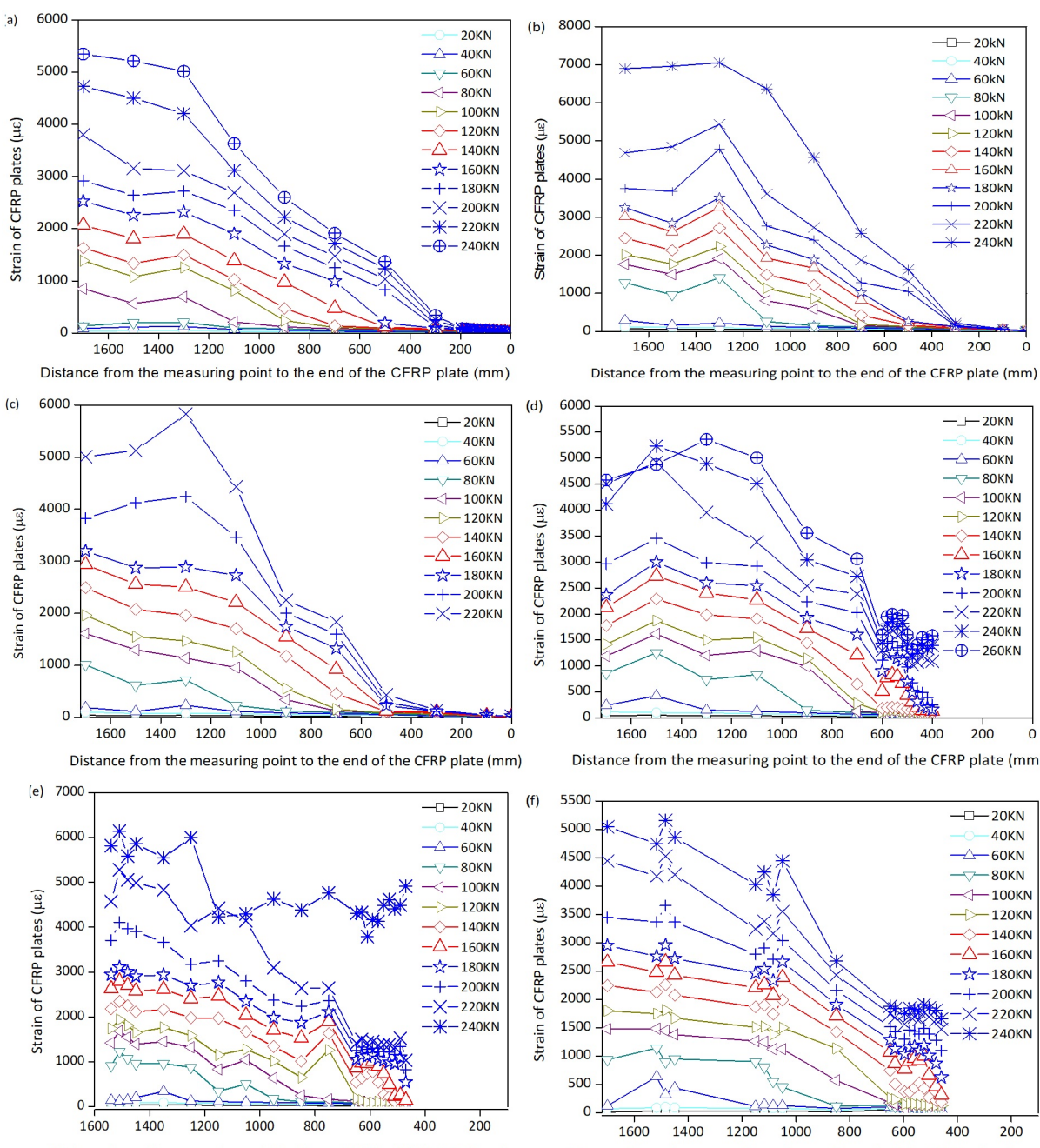

Distance from the measuring point to the end of the CFRP plate $(\mathrm{mm})$
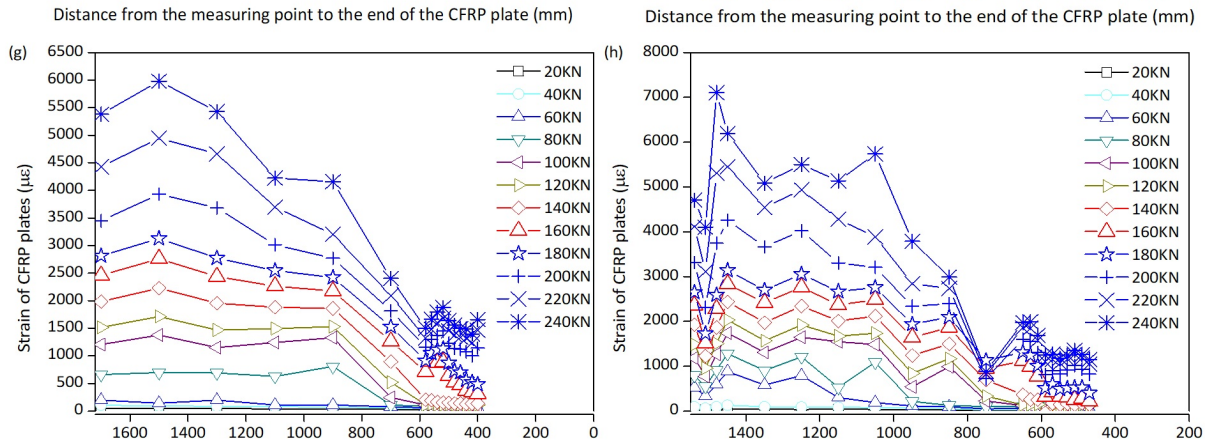

Distance from the measuring point to the end of the CFRP plate $(\mathrm{mm})$ Distance from the measuring point to the end of the CFRP plate $(\mathrm{mm})$

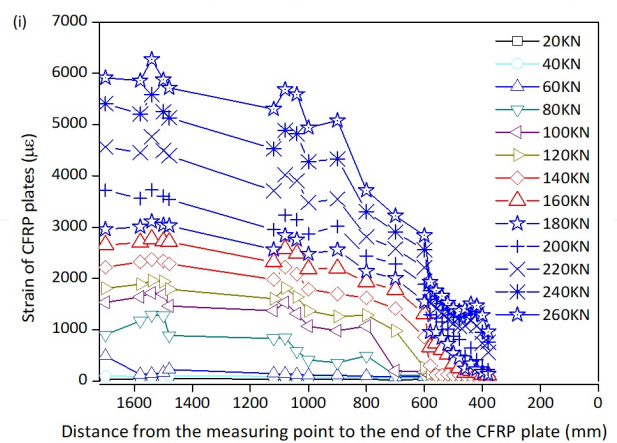

Figure 17 Strain distribution of CFRP plates under different level loads: (a) Specimen FX-1;(b) Specimen FX-2; (c) Specimen FX-3; (d) Specimen TM-1; (e) Specimen TM-2; (f) Specimen TM-3; (g) Specimen LM-1; (h) Specimen LM-2; and (i) Specimen LM-3. 


\section{THEORETICAL MODELS FOR DEBONDING BEARING CAPACITY}

Intermediate crack debonding (IC debonding) of CFRP-concrete interface is the dominant failure modes in CFRP reinforced bridge roof structure. Several researches have been carried out to investigate the IC debonding of CFRPconcrete interface failure and its influencing factors. Some models have been proposed to calculate the CFRP-concrete interface debonding failure (Leung et al., 2006; Lu et al., 2007; Said and Wu, 2008; Teng et al., 2003). The CFRP-concrete debonding failure model is introduced based on the test data and previous research results, the proposed CFRP-concrete debonding failure proposed model is compared with the previous CFRP-concrete debonding failure model. The validity and accuracy of the proposed model are presented in this paper.

\subsection{Existing theoretical models}

In order to assess the applicability of existing models in calculating the intermediate crack debonding bearing capacity of CFRP reinforced concrete components, the theoretical models proposed by Lu et al. (2004), Huang and Ye (2004), Teng et al. (2003), FIB 14 (2001) are analyzed in this paper. The adaptation range of these formulas is the midspan debonding failure of CFRP-reinforced reinforced test beams.

The symbols commonly used in the formulas below are uniformly described in this paper. $\varepsilon_{f, d b}, \sigma_{f, d b}, E_{f}, t_{f}, n_{f}$, $b_{f}, u_{f}, A_{f}, \Delta \sigma_{f}, \varepsilon_{f}^{u}, f_{f}^{u}$ represent the debonding strain, debonding stress, elasticity modulus, thickness, number of layers, width, bond length, stress increment, ultimate strain, ultimate tensile strength, respectively. $E_{s}, A_{s}, u_{s}$ are the elastic modulus of the steel bar in the tension zone, the area of steel bar, and the bond length of steel bar, respectively. $b_{c}$, $h, h_{0}$ are the width, height and the effective height of the flexural member, respectively; $f_{c}, f_{c}^{\prime}, f_{t d}$ are the design value of concrete compressive strength, the standard 28-day cylinder strength of concrete and the design value of concrete tensile strength, respectively; and $C, X$ are the thickness of concrete cover and the depth of concrete compression zone, respectively. $G_{a}, t_{a}$ are the shear modulus and thickness of the adhesive layer, respectively. $M_{d b}, M_{u}^{\prime}$ are the section debonding moment and critical section flexural bearing capacity, respectively. $l_{m}, L_{d}, L_{a}$ are the mean crack width, the bond length of FRP and the effective bond length of CFRP, respectively.

Lu et al. (2004) proposed a calculation formula for IC-debonding bearing capacity, based on finite element simulation and data regression, as follows:

$$
\begin{aligned}
& \varepsilon_{f, d b}=\left(0.492 / \sqrt{E_{f} t_{f}}-0.086 / L_{d}\right) \tau_{\max } \\
& \tau_{\max }=1.5 \beta_{w} f_{t} \\
& \beta_{w}=\sqrt{\left(2.25-b_{f} / b_{c}\right) /\left(1.25+b_{f} / b_{c}\right)} \\
& L_{d} \geq 0.76 \sqrt{E_{f} t_{f}}
\end{aligned}
$$

where $\tau_{\max }$ is the maximum of the bond shear stress, and $\beta_{w}$ is the coefficient of width.

Huang and Ye (2004) used finite element analysis and experimental methods to propose the formula as follows:

$$
\varepsilon_{f, d b}=\frac{\tau_{\max }\left(L_{d}+150\right)}{2 E_{f} t_{f}}
$$

Teng et al. (2003) corrected the formula of the in-plane shear-debonding bearing capacity, and proposed a calculation formula for the debonding bearing capacity caused by IC-debonding as follows:

$$
\begin{aligned}
& \varepsilon_{f, d b}=0.48 \beta_{w} \beta_{L} \sqrt{\sqrt{f_{c}^{\prime}} /\left(E_{f} t_{f}\right)} \\
& \beta_{L}=\left\{\begin{array}{cll}
1 & \text { if } & L_{d} \geq L_{a} \\
\sin \left[\pi L_{d} /\left(2 L_{d}\right)\right] & \text { if } & L_{d}<L_{a}
\end{array}\right.
\end{aligned}
$$


$\beta_{w}=\sqrt{\left(2-b_{f} / b_{c}\right) /\left(1+b_{f} / b_{c}\right)}$

$L_{d}=2 \sqrt{E_{f} t_{f} / \sqrt{f_{c}^{\prime}}}$

where $\beta_{L}$ is the coefficient of length.

The debonding failure predicted by using the crack width in FIB 14 (2001) was assessed based on the following equations:

$w=2.1 \rho_{c, e f f} \frac{M_{d b}}{E_{s} h_{0} \rho_{e q}\left(u_{s}+u_{f}\right)}$

$\rho_{\mathrm{c}, e f f}=\frac{A_{c, e f f}}{b_{c} h_{0}}$

$\rho_{e q}=\frac{A_{s} E_{s}+A_{f} E_{f}}{E_{s} b_{c} h_{0}}$

$A_{c, e f f}=\min \left[2.5\left(h-h_{0}\right) b_{c},(h-x) b_{c} / 3\right]$

where $\rho_{c, e f f}$ is the effective area ratio of concrete, and $A_{c, \text { eff }}$ is the effective tensile area of concrete, $\rho_{e q}$ is equivalent reinforcement ratio.

\subsection{The proposed theoretical model}

When the width of the curved main crack is equal to twice the crack width of the CFRP-concrete interface bond slip, the corresponding load value is equal to the peeling capacity of the CFRP-reinforced specimen. Based on the abovementioned crack debonding criterion, a new calculation method of bearing capacity is proposed, and a unified analysis model for evaluating debonding is established. The proposed model can be used to calculate the peel load capacity relatively accurately. It is derived from the theoretical and numerical investigation conducted in this paper.

The crack width in the crack debonding criterion (FIB, 2001; Lu et al., 2004) is described as the deformation difference between the FRP and the concrete in the two adjacent cracks. The crack width of the concrete at the height of the FRP can be derived by the following equations:

$$
\begin{aligned}
& w_{f m}=\varepsilon_{f m} \alpha_{c f} l_{m} \\
& \varepsilon_{f m}=\psi_{f} \varepsilon_{f} \\
& \alpha_{c f}=1-\varepsilon_{c m} / \varepsilon_{f m}
\end{aligned}
$$

where $w_{f m}, \varepsilon_{f m}, \alpha_{c f}$ are the average crack width, the average strain of CFRP at cracking section and the influence coefficient of concrete tensile between cracks on crack width, respectively. $\psi_{f}, \varepsilon_{f}, \varepsilon_{c m}$ are the non-uniformity of the FRP strain, the tensile strain of the CFRP in the crack region, and the average tensile strain of the concrete..

The tensile strain of the FRP at the crack section ${ }^{\varepsilon_{f}}$ can be calculated by Equation 17:

$$
\varepsilon_{f}=\frac{M}{\eta_{f} h_{f} E_{f} A_{f}\left[1+0.97 \frac{E_{s} A_{s} h_{0}^{2}}{E_{f} A_{f} h_{f} h}\right]}
$$


where $M$ is the section flexural moment, $\eta_{f}$ is the internal arm coefficients of CFRP and it is suggested to take as 0.95 in Lin et al. (2019).

The maximum crack width is related to the average crack width, and when the maximum crack width is equal ${ }^{2 \mathrm{~s}_{0}}$, the CFRP-reinforced specimen is considered to have debonding damage and can be calculated by the following equations:

$$
\begin{aligned}
& w_{f \max }=2 \mathrm{~s}_{0} \\
& \mathrm{~s}_{0}=0.0195 \beta_{w} f_{t} \\
& \beta_{w}=\sqrt{\frac{2.25-b_{f} / b_{c}}{1.25+b_{f} / b_{c}}}
\end{aligned}
$$

where $w_{f \max }$ is the maximum value of the average crack width $w_{f m}, \mathbf{s}_{0}$ is the interface slip displacement, $\beta_{w}$ is a coefficient related to the maximum bond shear stress $\tau_{\max }$ proposed in Lu et al. (2004).

Submit Eq. (14), Eq. (15), Eq. (16), Eq. (17), Eq. (19) and Eq. (20) into Eq. (18), the debonding moment of CFRP plate can be derived as follows:

$$
M_{d b}=\frac{0.03705}{k \alpha_{c f} \psi_{f}} \sqrt{\frac{\left(2.25-b_{f} / b_{c}\right)}{\left(1.25+b_{f} / b_{c}\right)}} h_{f} E_{f} A_{f}\left[1+0.97 \frac{E_{s} A_{s} h_{0}^{2}}{E_{f} A_{f} h_{f} h}\right] \frac{f_{t}}{l_{m}}
$$

where $k$ is the coefficient related to the section flexural moment $M$

The interface slip displacement ${ }^{s_{0}}$ corresponding to the maximum bond shear stress ${ }^{\tau_{\max }}$ can be calculated by the method proposed by Lu et al. (2004), and the formulas are as follows:

$\mathrm{s}_{0}=0.0195 \beta_{w} f_{t}$

$\tau_{\max }=1.5 \beta_{w} f_{t}$

$\beta_{w}=\sqrt{\frac{2.25-b_{f} / b_{c}}{1.25+b_{f} / b_{c}}}$

$k \alpha_{c f} \psi_{f} \frac{M_{d b}}{0.95 h_{f} E_{f} A_{f}\left[1+0.97 \frac{E_{s} A_{s} h_{0}^{2}}{E_{f} A_{f} h_{f} h}\right]} l_{m}=2 \times 0.0195 \sqrt{\frac{\left(2.25-b_{f} / b_{c}\right)}{\left(1.25+b_{f} / b_{c}\right)}} f_{t}$

The experimental data derived in this paper and previous work in $\mathrm{Hu}$ (2013), Wu (2002), Xie et al. (2009) and Ye et al. (2003) were used to fitted the proposed model. The suggested value was substituted into the Eq. (21), and the debonding moment $M_{d b}$ can be simplified as follows:

$$
M_{d b}=0.109 \sqrt{\frac{\left(2.25-b_{f} / b_{c}\right)}{\left(1.25+b_{f} / b_{c}\right)}} h_{f} E_{f} A_{f}\left[1+0.97 \frac{E_{s} A_{s} h_{0}^{2}}{E_{f} A_{f} h_{f} h}\right] \frac{f_{t}}{l_{m}}
$$

where the average cracking distance $l_{m}$ is calculated by the following equations:

$$
l_{m}=3.347 c+0.0367 \frac{\alpha_{f}\left(1+\frac{1}{\gamma}\right)}{4 \frac{\tau_{s m}}{f_{t}} \frac{\rho_{s}}{d}+\frac{\tau_{f m}}{f_{t}} \frac{\rho_{f}}{t_{f}}}
$$


$\alpha_{f}=\frac{b_{f}}{B+6 a_{f}}$

$\gamma=1.03 \frac{h}{h_{0}} \frac{E_{f} A_{f}}{E_{s} A_{s}}$

$\rho_{s}=\frac{A_{s}}{A_{c}}$

$\rho_{f}=\frac{A_{f}}{A_{c}}$

$A_{c}=b_{c} h$

$\frac{\tau_{s m}}{f_{t}}=1.6+0.7 \frac{c}{d}+20 \frac{\pi}{4 c_{s v}} \frac{d_{s v}^{2}}{s_{s v}}$

where $\alpha_{f}$ is the CFRP plate sticking coefficient (Figure 18 shows the calculation model of the CFRP plate sticking coefficient); $\rho_{s}, \rho_{f}, A_{c}$ are the reinforcement ratio, CFRP ratio of CFRP reinforced concrete flexural members and the cross section area of the concrete member, respectively; $\tau_{f m} / f_{t}$ is the ratio of average bond shear stress to concrete tensile strength, and it is suggested to equal 1.25 by Ceroni and Pecce (2009), and $\tau_{s m} / f_{t}$ is the ratio of bond stress between steel and concrete to tensile strength of concrete as recommended in Lam and Teng (2001), where $c_{s v}$, $d_{s v}$ and $s_{s v}$ are the concrete cover thickness, diameter and the spacing of the stirrups, respectively.

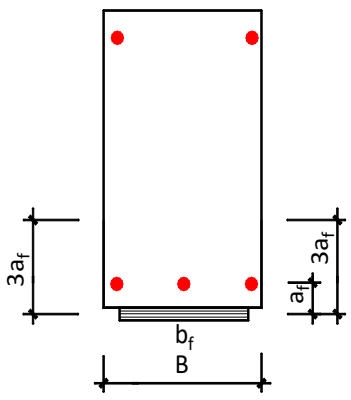

Figure 18 Calculation model of CFRP plate sticking coefficient.

The debonding bearing capacities of the specimens in the tests were calculated by the suggested model given in this paper and the models suggested by Lu et al. (2004), Huang and Ye (2004), Teng et al. (2003) and FIB 14 (2001) respectively. Table 5 lists comparison of the debonding moment $\left(M_{d b}\right)$ derived from the tests and different theoretical models.

Table 5 Comparisons of the debonding moment derived from the tests and theoretical models (unit: $\mathrm{kN} \cdot \mathrm{m}$ ).

\begin{tabular}{ccccccccccc}
\hline Specimen number & FX-1 & FX-2 & FX-3 & TM-1 & TM-2 & TM-3 & LM-1 & LM-2 & LM-3 & Average error* \\
\hline Test results & 168.0 & 168.0 & 154.0 & 182.0 & 168.0 & 196.0 & 168.0 & 168.0 & 182.0 & $/$ \\
The proposed model & 149.3 & 149.3 & 149.3 & 149.3 & 149.3 & 149.3 & 149.3 & 149.3 & 149.3 & 23.4 \\
Model in Lu et al. (2004) & 136.3 & 136.3 & 136.3 & 136.3 & 136.3 & 136.3 & 136.3 & 136.3 & 136.3 & 36.4 \\
Model in Huang and Ye (2004) & 140.8 & 140.8 & 140.8 & 140.8 & 140.8 & 140.8 & 140.8 & 140.8 & 140.8 & 31.8 \\
Model in Teng et al. (2003) & 129.2 & 129.2 & 129.2 & 129.2 & 129.2 & 129.2 & 129.2 & 129.2 & 129.2 & 43.5 \\
Model in Fib 14 (2001) & 85.2 & 85.2 & 85.2 & 85.2 & 85.2 & 85.2 & 85.2 & 85.2 & 85.2 & 87.5 \\
\hline
\end{tabular}

* The average error of each model is obtained from averaging the differences between the calculated values by the theoretical models and the test values of specimens. 
It can be seen from Table 5 that the average error of the proposed model is the lowest among all the theoretical models. The average error of the values calculated by the proposed model is $23.4 \mathrm{kN} \cdot \mathrm{m}$, which is much smaller than those of other theoretical models, such as the FIB 14 model $(87.5 \mathrm{kN} \cdot \mathrm{m}, 273.9 \%$ larger than that of the proposed model). It indicates that the model proposed in this paper has good predictive ability for the calculation of debonding moment between CFRP plate-concrete interface. It is worth noting that the calculation results are the same for different test specimens. This is because the current models cannot take into account the effects of different anchoring measures. Thus, further research is needed to establish a theoretical calculation model that can consider the influences of the anchoring methods.

\section{CONCLUSIONS}

This paper investigated the crack and mechanic behavior of CFRP plate-reinforced bridge roof under high temperature. Six CFRP-reinforced test beams with different anchoring schemes were designed and constructed. The beam specimens, after the high temperature effect, were tested under four-point bending loads. The crack propagation, load-deflection curves, load-strain curve, and failure modes of specimens of different reinforcement schemes were observed and recorded. A theoretical model was proposed for calculating the debonding bearing capacity of the CFRPconcrete interface. The following conclusions can be drawn:

1. The CFRP plate has a good inhibitory effect on the crack propagation. The CFRP plate-reinforced test beams exhibit higher load carrying capacity than the un-reinforced test beams.

2. Additional anchoring can effectively delay the occurrence of CFRP plate debonding. The debonding ductility and bearing capacity of the test specimens are both improved with the additional anchoring measures.

3. The additional anchoring measures placed at the mid-span and support positions are more effective in reducing the maximum crack width and the mean crack spacing of the test specimens.

4. The calculating results of the debonding bearing capacity by proposed theoretical model agree well with the experimental results. The model proposed in this paper could be applied to calculate the debonding bearing capacity of the CFRP plate-reinforced bridge roofs.

\section{Acknowledgements}

This work was financially supported by the National Natural Science Foundation of China (Grant Nos. 51508368, 51508276), the Postgraduate Research \& Practice Innovation Program of Jiangsu Province (Grant No. SJCX18_0879), and the Key Project of Innovation and Entrepreneurship of College students in Jiangsu Province (Grant No. 201810332019Z).

Author's Contributions: Conceptualization, $X$ Yuan and $Y$ Zhang; Methodology, $X$ Yuan and $Y$ Zhang; Investigation, $X$ Yuan, C Zhu, J Hu and $Y$ Zhang; Writing - original draft, $X$ Yuan, $C$ Zhu and J Hu; Writing - review \& editing, $X$ Yuan and $Y$ Zhang; Funding acquisition, $X$ Yuan and $Y$ Zhang; Resources, $X$ Yuan and $C$ Zhu; Supervision, $Y$ Zhang.

Editor: Marco L. Bittencourt.

\section{References}

Abbasloo, A., and Maheri, M.R. (2017). Prediction of modal damping of FRP-honeycomb sandwich panels with arbitrary geometries. Latin American Journal of Solids and Structures 14: 17-35.

Al-Mahaidi, R., and Kalfat, R. (2011). Investigation into CFRP laminate anchorage systems utilising bi-directional fabric wrap. Composite Structures 93(4): 1265-1274.

Biosca, J., Fabra, G., Vercher, J., Soriano, M., Lopez, G., and Tormo, S. (2019). Influence of high temperatures on concrete pillars confined with CFRP. Applied Mechanics and Materials 887: 64-71.

Ceroni, F., and Pecce, M. (2009). Design provisions for crack spacing and width in RC elements externally bonded with FRP. Composites Part B: Engineering 40(1): 17-28. 
Ceroni, F., and Pecce, M. (2010). Evaluation of bond strength in concrete elements externally reinforced with CFRP plates and anchoring devices. Journal of Composites for Construction 14(5): 521-530.

Chen, X. C., Ding, M. B., Zhang, X. Y., Liu, Z. W., and Ma, H. J. (2018). Experimental investigation on seismic retrofit of gravity railway bridge pier with CFRP and steel materials. Construction and Building Materials 182: 371-384.

Cheng, H.X. (2016). Effect of temperatures on interfacial bonding strength ofcarbon fiber/epoxy resin composites. Ph.D. Thesis (in Chinese), Donghua University, China.

Ferrier, E., and Agbossou, A. (2017). Temperature effects on the shear capacity of external bonded fiber reinforced polymer on concrete. Construction and Building Materials 152: 333-344.

FIB. (2001). Externally bonded FRP reinforcement for RC structures, in: Bulletin 14.

Galal, K., and Sekar, M. (2008). Rehabilitation of RC inverted-T girders using anchored CFRP plates. Composites Part B: Engineering 39(4): 604-617.

Hong, L., Zhang, Y., and Wang, S. (2016). The interface behavior of CFRP-high strength concrete under freeze-thaw cycles. Journal of Water Resources and Architectural Engineering 14(3): 200-205.

Hosseini, A., Ghafoori, E., Al-Mahaidi, R., Zhao, X. L., and Motavalli, M. (2019). Strengthening of a 19th-century roadway metallic bridge using non-prestressed bonded and prestressed unbonded CFRP plates. Construction and Building Materials 209: 240-259.

Hu, J.B. (2013). Research on the force preformance of concrete flexural member reinforced by CFRP laminates with high performance. Ph.D. Thesis (in Chinese), Southeast University, China.

Huang, Y.I., and Ye, L.P. (2004). Nonlinear FEM analysis on bond behavior of RC beams strengthened with bottom bonnded CFRP sheets. Engineering mechanics 21(2): 54-61.

Jiang, S., Hou, J., and He, Y. (2015). Study on limit state reliability of reinforced concrete beams strengthened with CFRP tendon sheet considering pre-stress loss. China Civil Engineering Journal (11): 36-43.

Kohnehpooshi, O., and Jaafar, M.S. (2017). Non-linear three dimensional finite elements for composite concrete structures. Latin American Journal of Solids and Structures 14: 398-421.

Kondratenko, M. S., and Ding, N. H. (2018). The reasons of destruction of reinforced concrete beams with carbon fiber reinforced polymer (CFRP)-measures for prevention such destruction. Young Scientist 1(53): 434-437.

Lam. L, and Teng, J. G. (2001). Strength of RC cantilever slabs bonded with GFRP strips. Journal of Composites for construction 5(4): 221-227.

Leung, C.K., Ng, M.Y., and Luk, H.C. (2006). Empirical approach for determining ultimate FRP strain in FRP-strengthened concrete beams. Journal of composite for construction 10(2): 125-138.

Lin, J.X., Huang, P.Y., Guo, X.Y., Zheng, X.H., and Zhao, C. (2019). Fatigue performance of RC beams strengthened with CFRP under coupling action of temperatures and vehicle random loads. Fatigue and Fracture of Engineering Materials and Structures 42: 31-44.

Lopez, M. M., Naaman, A. E., Pinkerton, L., and Till, R.D. (2003). Behavior of RC beams strengthened with frp laminates and tested under cyclic loading at low temperatures. International Journal of Materials and Product Technology 19(1): 108-117.

Lu, X.Z., Teng, J.G., Ye, L.P., and Jiang, J.J. (2004). Bond-slip models for FRP sheets/plates bonded to concrete. Engineering Structures 27(6): 920-937.

Lu, X.Z., Teng, J.G., Ye, L.P., and Jiang, J.J. (2007). Intermediate crack debonding in FRP strengthened RC beam: FE analysis and strength model. Journal of Composites for Construction 11(2): 161-174.

Luo, S.S. (2018). study on fatigue performance of reinforced concrete (RC) beams strengthened with carbon fiber reinforced polymer (CFRP) in hot-seawater environment. Ph.D. Thesis (in Chinese), South China University of Technology, China.

Mashrei, M.A., Makki, J.S., and Sultan, A.A. (2019). Flexural strengthening of reinforced concrete beams using carbon fiber reinforced polymer (CFRP) sheets with grooves. Latin American Journal of Solids and Structures, 2019, 16(4): e176.

Mertoğlu, C., Anil, Ö., and Durucan, C. (2016). Bond slip behavior of anchored CFRP strips on concrete surfaces. Construction and Building Materials 123: 553-564. 
Qazi, S., Michel, L., and Ferrier, E. (2013). Experimental investigation of CFRP anchorage systems used for strengthening RC joints. Composite Structures 99(5): 453-461.

Said, H., and Wu, Z. (2008). Evaluating and proposing models of predicting IC Debonding Failure. Journal of Composites for Construction 12(3): 284-299.

Shukri, A.A., Shamsudin, M.F., Ibrahim, Z., Alengaram, U.J., and Hashim, H. (2018). Simulating intermediate crack debonding on RC beams strengthened with hybrid methods. Latin American Journal of Solids and Structures 15(9): e78.

Teng, J.G., Smith, S.T., Yao, J., and Chen, J.F. (2003). Intermediate crack-induced debonding in RC beams and slabs. Construction and Building Materrials 17(6-7): 447-462.

Wang S., Yao, Y., and Hong, L. (2017). Durability of FRP-high strength concrete adhesive joints under aggressive exposure conditions and loads. Journal of Disater Prevention and Mitigation Engineering 37(1): 127-133.

Wu, G. (2002). Experimental study and theortical analysis on strengthening concrete structures with FRP. Ph.D. Thesis (in Chinese), Southeast University, China.

Wu, Y.F., Yan, J.H., Zhou, Y.W., and Xiao, Y. (2010). Ultimate strength of reinforced concrete beams retrofitted with hybrid bonded fiber-reinforced polymer. ACI Structural Journal 107(4): 451-460.

Xie, J.H., Huang, P.Y., Guo, X.Y., and Deng, J. (2009). Analysis of intermediate shear stress in cracked RC beams strengthened with FRP. Engineering Mechanics 26(11): 127-133.

Yang, Z., Tan, T., and Liu, Y. (2017). Experimental study on prestressed CFRP reinforced concrete bridge deck. Journal of Highway and Transportation Research and Development 34(08): 76-82.

Ye, L.P., Fang, T.Q., Yang, Y.X., and Yue, Q.R. (2003). Experimental research of flexural debonding perforamnce about RC beams strengthened with CFRP sheets. Buliding Structure 2: 61-65. 